\title{
Androgyny in the Mirror of Self-Actualisation and Spiritual Health
}

\author{
Itai Ivtzan* and Rita Conneely
}

Department of Psychology, UCL (University College London), 26 Bedford Way, London WC1H 0AP, Office 413

\begin{abstract}
This study evaluates issues concerning the potential relationship between androgyny (incorporating both male and female features) and Self-Actualisation (fulfilment of one's fullest potential) while evaluating their role in feminine and non-feminine occupations. 119 participants (half employed in Traditionally-Feminine occupations and the other half in Non-Feminine jobs) answered the Bem Sex Role Inventory (BSRI) and the Personal Orientation Inventory (POI). Those deemed to possess an Androgynous Gender Role, by the BSRI, were found to be significantly more Self-Actualised across almost the entire range (ten out of twelve) of the POI scales, than those of Non-Androgynous Gender Identities. Thus, the long argued and conflicting assertion for the Self-Actualising benefits of an Androgynous Gender Identity are supported by the current study. No differences were found between the prevalence of Androgyny or achievement of SelfActualisation between the Experimental (those employed in typically-female fields) and Control (those engaged in traditional-gender or gender-non-specific work) occupation groups; although significant lower numbers of Masculine Men in the Experimental group do verify that Gender Roles continue to be an influential occupational factor.
\end{abstract}

\section{INTRODUCTION}

Gender is so imperative to our self-image it is allowed to determine everything from behaviours, appearances and even occupational choices [1]. Maslow (1968) [2] argued that we are motivated by a wide variety of factors, depending on our current mind-set, the demands placed upon us and the goals we wish to achieve. Within this framework, people can move 'beyond' restrictive identities (for example, from an exclusive gender to a more integrated sense of Androgyny) to make decisions based on self-determined values and characteristics; thereby progressing towards the pinnacle of Maslow's (1943) [3] 'Hierarchy of Needs' - Self-Actualisation. Consequently, our behaviours would reflect this internalised fundamental attitude, demonstrating to others our greater social competence.

Occupational choice is just one example of how our actions are often assumed to be somehow indicative of our personalities (for example, an artist is considered to be creative, a lawyer is considered shrewd), despite historically being more often determined by socio-economic requisites influenced by norms [4]. This remains the case for femalegender occupations in particular - the care of children and the household being perceived as the domain of women alone [5]. Perhaps then it is amongst those who pursue careers which still possess such highly gendered connotations (for example, men in feminine-type jobs) that the acceptance of a non-stereotyped Gender Concept (Androgyny) and an appreciation for a wider scope of personal motivational issues, aside from mere societal conventions (as found in the Self-Actualised), will most frequently arise.

*Address correspondence to this author at the Department of Psychology, UCL (University College London), 26 Bedford Way, London WC1H 0AP, Office 413; E-mail: i.ivtzan@ucl.ac.uk

\section{A New Gender Role: The Theory of Androgyny}

Gender has always been known as a bi-polar construct; as early as 1387-8, Thomas Usk stated 'No [more] genders been there but masculine, and feminine' [6]. However, despite Freud's assertion that 'Anatomy is Destiny' [7], the factors which actually contribute to an individual's Gender Identity encapsulate all aspects of humanity; from perspectives and behaviours in the home, workplace and throughout society $[8,9]$. Thus, while the term 'Sex' has been commonly used, Gender Role is now generally deemed more appropriate, reflecting the variety of features, beyond mere biology, which are perceived to be gender-specific. Historically though, there is no doubt that the gender stereotyping of characteristics arose from physically salient differences; men being the stronger and therefore the 'conqueror' in primitive hunter-gather societies, while women, as the child bearers, developed skills focused on nurturance and responsibility $[10,11]$. This basic distinction remains common throughout all trait theories; whether Parson and Bales' (1955) [12] Instrumental and Expressive dimensions Guttmann's (1965) [13] Impersonal and Personal orientations or Bakan's (1966) [14] modalities of Agency and Communion. A meta-analysis conducted by Feingold (1994) [15] supported the gender differences shown by Maccoby and Jacklin (1974) [16] in adult personality traits, illustrating that women score lower than men on assertiveness and higher on extroversion, anxiety, trust and nurturance. Similarly, in Costa, Terracciano, and McCrae (2001) [17] higher rates of Neuroticism, Agreeableness, Warmth, and Openness to Feelings were found for women, while men were higher in Assertiveness and Openness to Ideas.

Accordingly, typically masculine characteristics include achievement, assertiveness and independence, whereas femininity is ideally manifested through conscientiousness, docility and co-operation [10]. These highly sex-typed 
Gender Ideals are reinforced through socialisation, with success and psychological well-being ensured by emulating the appropriate Gender Role; that is, performing the behaviours attributed to one's own anatomical gender and rejecting those credited to the opposite sex $[18,19]$.

However, in 1973, Block suggested that successful moral advancement, and therefore psychological maturity, was best enabled not by a strict adherence to traditional Gender Roles, but in the recognition of a Gender Identity secure enough to express both Agency (primarily an ego-centric, assertive, and so, more masculine personality) and Communion (a more feminine perspective which understands and appreciates the individual as part of a larger system). Block identified this behavioural pattern as an androgynous sex role, emphasising its non-partisan nature, as it incorporated both male and female features. Psychological Androgyny therefore can be applied to describe individuals with both stereotypic masculine and feminine behavioural traits $[8,20]$.

Subsequently, the Bem Sex Role Inventory (BSRI; Bem, 1974) [21] was developed to specifically identify Androgynous individuals; a characteristic overlooked by all Gender Role measures at the time. Bem argued that established Gender Role measures treated 'paired' traits, for example, Forceful and Soft-Spoken, as mutually exclusive, thereby inherently propagating a divisive view of gender. Bem's inventory was swiftly followed by Spence, Helmreich and Stapp's (1974) [22] Personal Attributes Questionnaire $(P A Q)$; illustrating that the existence of an alternative more integrated Gender Identity was becoming accepted. It is therefore the manifestation of a high number of masculine alongside a high number of feminine traits that these scales classify as Androgyny. According to Bem [1, 8, 21, 23], this integration and active expression of both gender's characteristics equips the individual with a greater repertoire of skills and enhanced behavioural flexibility with which to respond to the range of social experiences encountered. This is particularly important in the rapidly evolving modern environment. Whereas once people were ensured, for example, a job for life, the current workplace requires us to perform under constant review; threatened by youth, foreign labour or, more often, technological advances (Russell \& Bowman, 2000) [24]. Equally, the home is no longer the bastion of stability traditionally revered by Parsons and Bales (1955) [12] as embodying the best collaboration of Instrumental and Expressive roles, through the ideal father/husband and ideal mother/wife partnership (Nettles \& Loevinger, 1983) [25]. Families now consist of a variety of structural arrangements; from single parents to the linking of numerous sub-units through half-sisters and stepbrothers [26]. This might require individuals to undertake roles and activities which traditionally were not expected of them. By internalising an Androgynous Gender Role however, the skills which prove advantageous in two completely opposing situations would both be available to the individual; therefore encouraging a greater degree of social success [27].

This assertion, of the more extensive capabilities supplied by an Androgynous behavioural style, is also supported empirically. Bem (1975) [23], for example, found that Androgynous individuals (categorised by the BSRI) showed far greater cross-situational adaptability; demonstrating supposedly masculine independence during conformity and social pressure experiments, and more effeminate playfulness under different circumstances. Similarly, Bem, Martyna and Watson (1976) [28] found Feminine individuals to be the most nurturing in response to lonely fellow students, babies and kittens, but in the Androgynous this nurturing tendency was matched by their strong sense of independence, when under pressure to conform. Research is also associating androgyny with more satisfaction with life [29], subjective feelings of wellbeing [30], higher levels of creativity [31], more adaptive or flexible behaviour [32] and higher levels of optimal mental health [9].

Despite the advantages, the incidence of Androgyny is relatively low; accounting for only $21 \%$ of males and $29 \%$ of females in Bem's [23] sample. However, this is unsurprising when one considers the strength of the Gender Roles usually propagated by society; namely, the Masculine male and Feminine female. Bem and Lenney (1976) [33] clearly demonstrated this; when highly sex-typed individuals were presented with an array of supposedly gender-specific activities to be photographed performing, women preferred to 'prepare a baby bottle...' while men chose to '... oil squeaky hinges...' (pp. 50). This persisted even when they were offered significantly higher payments for the gender 'inappropriate' option. Furthermore, they reported feeling greater 'psychological discomfort' (pp. 53) and negative selfappraisal when non-typical activities were insisted upon. This also validates the BSRI as a true reflection of actual behaviours, confirming that there is consistency between the gender characteristics people attribute to themselves and the likelihood of them being displayed. Supporting the same idea, Vogel, Wester, Heesacker, and Madon (2003) [34] have since shown that when discussing an emotionally difficult topic, even those in a very close romantic relationship revert to traditional behaviour styles (confirming gender stereotypes) to ease their sense of vulnerability. Therefore, it appears that stereotypical Gender Schemas are both highly prevalent and well internalised in society, despite the behavioural limitations they may impose.

It appears then that an Androgynous Gender Role is not just a measure of the ability to appreciate the utility of both masculine and feminine behavioural traits, but also a reflection of greater psychological wellbeing [21, 35-37]. This is due to their reduced risk of cognitive conflict arising from potentially stressful experiences [10]; as they are motivated by values independent of society's norms, while still performing more than competently in social situations. It is these skills which are also inherent in the highly SelfActualising individual; commonly perceived by Maslow (1956) [38] as the ultimate goal of human motivation. Thus, could the reconciliation of the dichotomous nature of human gender, through the acceptance of Androgyny, be a defining indication of Self-Actualisation?

\section{Self-Actualisation: The Path to Self-Fulfilment}

The concept of Self-Actualisation arises in the work of many researchers; including Reisman's (1950) [39] 'Inner' and 'Outer-Directed' personalities, Perls' (1951) [40] Gestalt Psychology and Loevinger's Ego Development (1976) [41]. However, as mentioned earlier, it is best known as the peak of Maslow's (1943) [3] 'Hierarchy of Needs', in which various human motivations are categorised into a 
series of pre-potent stages, beginning with the most basic of Physiological needs, such as hunger and sleep. These are followed by Safety (including security of employment), Love/Social (successful relationships), Esteem (confidence and respect), Cognitive (increasing understanding) and Aesthetic needs (continued appreciation of beauty). This process always culminates in Self-Actualisation - the ultimate development of one's capabilities and thus fulfilment of one's potential. This broadly manifests in three ways [42]:

1) Sense of autonomy - being motivated not by social norms, but by a personal set of internalised morals;

2) Relationships with others - ensuring that their principles are not deliberately socially antagonistic, thereby meditating the previous (somewhat) egocentric attitude and encouraging a desire to assist others through 'problem-solving';

3) Perception of the world - demonstrating a repeated interest in and appreciation of humanity and the world, despite also having a realistic understanding of its inherent faults and injustices, thus intensifying their life experiences and interactions with others. Additionally, the exact manner in which these characteristics are expressed is highly idiosyncratic, thereby encompassing all talents and so, all people.

One of the greatest needs portrayed by self-actualisers is the need for meaningfulness. They carry a clear sense of meaning and purpose in their lives; this tendency reflects their spiritual health [43] which refers to a positive sense of belonging, meaning and purpose in life.

The introduction of the Personal Orientation Inventory (POI; Shostrom, 1966) [44] fulfilled the need for a standardized test of Self-Actualization (Maslow, 1993) [45]. Furthermore, it was considered particularly useful by Maslow (1968) [2] who stated that its attainment 'is a matter of degree and of frequency rather than an all-or-none affair' (pp. 97), indicating that such tests are relevant for the entire population; nonetheless, questions concerning cross-cultural relevance of the terms has been raised by Ivtzan (2008a) [46]. The Sentence Completion Test (SCT; Loevinger \& Wessler, 1970) [47] was designed with a similar aim in regards to Ego Development (where the stages of Autonomous and Integrated are equivalent to self-actualisation; [48]) and both are widely used in Self-Actualisation research. Indeed, with the aid of the POI Choy and Moneta (2002) [49] have shown a positive relationship between certain components of Self-Actualisation and life satisfaction, self regard and self esteem. Furthermore, Massuci (1966) [50], found that those who obtained high POI scores didn't see careers as solely a source of income or social prestige (unlike most of the population), reflecting Maslow's (1956) [38] argument that the Self-Actualised would be highly ethical people who see things as more than a means to an end. Likewise, a lack of fear of social judgement or exclusion is demonstrated by those with high POI scores through their greater assertiveness [51,52] and ability to trust their own opinion, instead of conforming, particularly on the Inner-Directed [53] and Spontaneity scales [54]. Significant work concerning the relationship between SelfActualisation and the highest levels of ego development, as measured by the SCT, has been conducted by Cook-Greuter
$(1999,2000)[55,56]$ who found that when reaching high stages of ego development the self actualised person can uphold a continuous openness to experience without any internal or external conflicts.

The parallels between those classified as Androgynous and heightened Self-Actualisation are unsurprising given the history behind the development of the former. As discussed previously, the very reason it was proposed that humanity should embrace this new Gender Identity were the psychological, cognitive, social and mental health advantages it produced $[10,21,57]$. Thus, as these abilities are improved by the ascent of the 'Hierarchy of Needs', and SelfActualisation embodies the epitome of their achievement [3], it seems implicit in the theory of Androgyny that such an identity is more Self-Actualising. Can the quantification of this highly idealistic concept (through the POI, for example) identify the specific features which would also enable the acceptance of Androgyny? And to what extent has empirical research substantiated this presumed association?

\section{Androgyny and Self-Actualisation}

The breadth of characteristics Maslow outlined as SelfActualising are well accounted for by the twelve separate scales Shostrom (1966) [44] included in the POI; each focusing on a particular aspect. However, when addressing those skills also utilised by the Androgynous, some are particularly relevant. The scales of Inner-Directedness, Spontaneity, Existentiality and Feeling Reactivity all relate to the ability to recognise internalised beliefs and needs and behave in a manner concurrent to them, rather than rigidly adhering to the rules of society (for example, that men should be solely masculine). Likewise, Nature of Man reflects the ability to acknowledge the inevitably dichotomous nature of humanity, while Synergy enables the understanding that these are related aspects of an integrated whole (exemplified by Gender). Additionally, as Androgyny represents the demonstration of both masculine and feminine behaviours, both Acceptance of Aggression (referring to traditionally masculine characteristics) and Capacity for Intimate Contact (focusing on issues generally conceived to be more feminine) are important. Thus, there appears to be a very strong conceptual relationship between the skills required to exhibit an Androgynous Gender Role (for example, synergism) and those which the $P O I$ uses to identify more Self-Actualising members of society.

Block (1973) [10] was the first to identify Androgynous skills and self-concepts within measures of psychological advancement. Block (1971) [58] asserted that that mature ego functioning was most evident in highly socialised but low gender-appropriate individuals; for example, men who achieved high Femininity scores. Similarly, Heilbrun (1968) [59] found that girls who embraced a greater degree of masculinity while also retaining aspects of their femininity were better adjusted than even their very feminine counterparts; contradicting traditional assumptions of the superiority of consistent Gender Identity. In addition, those identified as more Self-Actualising (by the POI) show less rigidity in their female stereotypes [60] and a more liberal and progressive (namely pro-feminist) attitude to women's prospects [61], again reflecting the theme of cognitive flexibility. Selfesteem, traditionally attributed primarily to men, has also 
proved to be higher amongst Androgynous women, whether classified by the $P A Q$ [62] or the BSRI; as was their level of Ego Development [63]. Men who demonstrated high levels of Ego Development [64] and Psychosocial Development [65] were also more likely to be categorised as Androgynous and engaged in less sex-typing. Reviewing the strong trend within much of this literature, Bursik (1995) [66] hypothesised that the expression of a non-traditional Gender Role necessitates a highly developed ego; subsequently confirming that men in the highest ego stages (the Autonomous and integrated) utilised significantly more $P A Q$ Expressive traits and achieved higher BSRI Femininity scores. Therefore, it appears that Androgyny is indeed a key indication of a more psychologically developed and actualised individual.

However, these conclusions are not comprehensive. For example, Schwarz and Robins (1987) [67] and Nettles and Loevinger (1983) [25] failed to find a significant relationship between increased Ego Development and an Androgynous Self-Concept; even though both indicated that those in the higher ego stages did expect others to endorse this Gender Role. Thus, the advantages of Androgyny appear to have been recognised by these individuals yet they still preferred their own Gender Identity, irrespective of this knowledge. These conflicting studies create further confusion by introducing other gender measures; the PRF ANDRO Scale [68] and the Sex Role Survey [25], respectively. Even within the existing body of supporting research there are methodological discrepancies; some studies determining Androgyny with the $P A Q$, while others opt for the BSRI. Although Bursik (1995) [66] did successfully acquire corresponding conclusions when directly comparing these last two measures, Kelly and Worrell (1977) [69] raised serious concerns over the validity of assuming that classifications of Androgyny are equivalent across various measures. Thus, clearer methodological selection processes must be employed to clarify the relationship between Androgyny and Self-Actualisation.

More concerning is the differential patterns which seem to arise between men and women, with many studies attributing their results to one gender only (e.g., Costos, 1986) [64]. Kelly, Caudill, Hathorn and O'Brien (1977) [70] suggested this was due to the greater perceived utility of masculine skills, such as leadership ability. This is particularly evident in Bursik (1995) [66]; some males being separately categorised as 'Hyper-Masculine', after endorsing Masculinity so highly (even attaining the maximum BSRI mean of 7) yet femininity very rarely. More interestingly however - no female equivalent arose; to reiterate - no woman saw an exclusively effeminate female as a Gender Ideal. The most 'developed' women also endorsed high levels of Instrumentality/masculinity relatively unmediated by Expressiveness/femininity; indicating not just a preference for masculinity (irrespective of gender) but that the assimilation of Instrumental traits posed no risk, even for women. At the same time, suggestions that Self-Actualisation is related to a specifically Masculine Gender Role (Guyot \& Vollemaere, 1983) [71] might be exaggerated; masculine individuals were showing significantly lower levels, in comparison with the Androgynous, on measures of selfesteem [62] and ego achievement [65].

\section{The Advent of the 'Manny'}

Today, $70.1 \%$ of women in the UK are employed [72]; the numbers in the US are 60\% [73] and 59\% in Australia [74]. Despite the accomplishments of this social revolution 'women's work' remains highly gendered; women being far more likely to be employed 'in a narrow range of occupations' which themselves are female-dominated and 'seen as being very similar to the role of the housewife' [5]. Thus, Nurses, Primary School Teachers [5, 75] and Child-Carers [76] are among the most recognised 'typically-female' occupations; each reflecting the characteristics inherent in a traditionally Female Gender Role. However, men are not unknown in these jobs and, more importantly, their presence is on the rise [77]. This is exemplified, anecdotally, by the popularity of the 'Manny' (or male nanny). This new trend illustrates that the benefits of a solely feminine Gender Identity in these roles is under question. Gauthier and Kjervik (1982) [78] for example, claim that nurses are increasingly required to be assertive, ambitious, and independent - all skills traditionally attributed to men. The ability to retain such masculinity may therefore attract men to jobs previously seen as inaccessible. However, this increasing demand for masculine traits does not diminish the established importance of feminine skills, such as compassion, care and understanding, in these roles [79]. Thus, it is an Androgynous Gender Role that can express both types of gendered skills which is now desirable in educators [79] and nurses [80-82]. While Gender Identity remains decisive in occupational choices [83], the Androgynous seem unhampered by the cognitive conflicts which non-traditional roles typically cause [84]. Thus, it seems likely that an Androgynous Gender Role will be a central feature in men choosing an occupation traditionally considered female [85].

However, these men are rare. While women have been highly successful at entering non-traditional careers [86-88]; facilitated by the relative ease with which they accept masculine characteristics, for men however, the association with femininity is far more contentious. For example, adults disapprove of displays of typically-female behaviours in boys significantly more than cross-typed behaviour in girls [89]. Similarly, Bagilhole and Cross (2006) [90] suggested that though women are applauded for crossing occupational gender-barriers, men are specifically not. Instead, they expect to be stigmatised (Muldoon \& O'Reilly, 2003) [84]; working with children, for instance, often eliciting assumptions of homosexuality or sexual perversion [91]. Thus, while $88 \%$ of young people thought a doctor or head-teacher was equally likely to be either male or female, $61 \%$ still believed childcare was only appropriate for women [76]. When men do risk the social prejudice of such work, they are not even rewarded with wealth or prestige in comparison with male occupations: the average male child-carer earning just $£ 281.20$ per week; comparatively, construction work averages at about $£ 413.20$, while the median earnings of all full-time males is $£ 498$ [92]. Therefore, there is clearly very little impetus for even androgynous men to pursue more feminine-type jobs.

As Self-Actualisation illustrates however, these external factors are not imperative in motivating the choices of all; wages for example, being merely a means to an end [50]. 
Instead, work which provides opportunities for solving problems which have real social ramifications would seem to be more attractive to the Self-Actualised; teachers, for example, being named 'the self-actualising professional' [93]. Nursing has also been credited with actually increasing POI scores over three years [94] and is related to a greater sense of job satisfaction [95, 96], altruism [97] and selffulfilment [98]. Thus, typically-female jobs seem to exemplify this Self-Actualising ethic; being primarily concerned with the care of others and requiring personalised, often innovative solutions. Additionally, the potential to be dissuaded by social judgement is further diminished by the highly self-determined nature of Self-Actualiser's decisionmaking. Therefore, it seems likely that a more SelfActualised attitude will also be noted in men employed in typically-female occupations.

\section{The Current Study}

Following the topics and questions discussed previously, three hypotheses are predicted within the current study:

1) The degree of Self-Actualisation attained on the Personal Orientation Inventory by those categorised as Androgynous by the Bem Sex Role Inventory is predicted to be significantly greater than that obtained by those with a Non-Androgynous Gender Identity (Masculine, Feminine and Undifferentiated).

2) The distribution of Gender Roles between the Experimental (men who are employed in an occupational field traditionally associated with women) and Control (men who are employed in non-gender-specific occupations) groups will be significantly different; it is predicted that Androgyny will be significantly more likely amongst the experimental group in comparison with the control group.

3) Furthermore, these atypical men will be significantly more Self-Actualised (again determined with the POI) than those with non-feminine occupations.

\section{METHOD}

\section{Participants}

106 male participants were recruited for this study. Fifty-three participants were identified as having typicallyfemale occupations and so assigned to the Experimental condition, while an equal number with non-female-typed jobs were randomly selected to form the Control group.

Within the Experimental group twenty participants were employed as Nurses, fifteen as general Child-Carers (for example, in After-School Clubs), and eighteen as Primary School Teachers. The mean Age for this group was 34.65 $(\mathrm{SD}=11.06)$, and ranged from 19 to 64 years.

The Control group reported a variety of occupations; both typically masculine (for example, construction) and gender non-specific (such as bank clerk). The mean Age was $33.44(\mathrm{SD}=15.15)$ and ranged from $18-66$ years.

\section{Materials}

Two main measures were utilised in this study, the BSRI (to identify Androgyny) and the POI (to measure SelfActualisation).

\section{Bem Sex Role Inventory (BSRI)}

The BSRI is the most widely used and validated Gender Role measure in publication [99]; reporting scale reliability coefficients from 0.75 to 0.9 [8]. It consists of a list of sixty attributes and behaviours; twenty of which were verified to be more socially desirable when demonstrated by men, twenty deemed more appropriate for women and twenty of no gender-affiliation. These are presented to the participant in a systemised order however, to prevent order or fatigue effects on overall Masculinity and Femininity scores, and dissuade them from recognising the true purpose of the measurement. This was further safeguarded by referring to this section as the 'Bem Inventory' in all participant literature, thereby removing the possible bias of their associations with the terms Sex or Gender. Participants rated each attribute according to 'How True of themselves' they perceived each to be; on a scale running from one (Always or Almost Always Never) to seven (Always or Almost Always). Thus, the $B S R I$ is completed by simply writing a number from one to seven beside all sixty words. Based on the analysis of these ratings, four Gender Roles are identified: 1) Androgynous- those whose scores fall above the population Masculinity and Femininity medians (and therefore claim to possess a high number of both masculine and feminine attributes); 2) Feminine- those whose Masculinity scores fall below the population median, but have Femininity scores greater than the median (thus being considered to possess a largely effeminate behavioural style); 3) Masculine- scoring above the median on Masculinity but below on Femininity (therefore being deemed more masculine); and 4) Undifferentiated. This last group represent those individuals whose ratings may be of a comparable level across the gender distinction but also fall much lower than those attained by the rest of the population (as both their Masculinity and Femininity scores are lower than the respective medians). The separation of these individuals from the larger Androgynous cohort (in accordance with Bem, 1976, and Spence et al, 1975) [22, 28] is essential, as they have proven to perform less competently than both high scoring Androgynous individuals and even highly sex-typed peers, with regards to a variety of social and psychological factors (Flaherty \& Dusek, 1980; Glazer \& Dusek, 1985; Waterman \& Whitbourne, 1982) [100-102]. Therefore, identification with an Undifferentiated Gender Role is clearly not what the BSRI intends to quantify as Androgyny [28].

\section{Personal Orientation Inventory (POI)}

The POI was explicitly chosen for this study for a number of reasons. It is extensively used in a far wider context and is highly validated on test-retest reliability (Klavetter \& Morgan, 1967, reporting coefficients from 0.52 to 0.82 ) [103], shown to be relatively stable over time [104], and uninfluenced by social desirability $[105,106]$ even crossculturally [107], validating it as a measure of actual beliefs. Furthermore, the numerical nature of the POI means that it is more sensitive to the individual's relative achievement along a Self-Actualising 'continuum'. Finally, it has specifically been endorsed by Maslow (1968) [2] as the most appropriate measure of Self-Actualisation and so is essential for the clarification of the currently conflicting research reviewed.

The $P O I$ itself is a comparative value questionnaire consisting of 150 items; each taking the form of two con- 
trasting statements addressing the same issue, from which the subject must pick that which applies to them best.

These items are then providing the score for the following twelve POI scales:

- Time-Competence (TC; being present-orientated)

- Inner-Directed $(I$; being independent and internally motivated)

- Self Actualising Value ( $S A V$; expressing the primary Self Actualising values)

- Existentiality (Ex; not rigidly adhering to principles)

- Feeling Reactivity ( $\mathrm{Fr}$; ability to sensitively respond to the needs and feelings of others and oneself)

- Spontaneity ( $S$; behaving true to oneself, without fear)

- Self Regard ( $\mathrm{Sr}$; recognising one's own strength and worth)

- Self Acceptance ( $\mathrm{Sa}$; recognising one's own failings)

- Nature of Man ( $\mathrm{Na}$; having a positive view of man's nature and dimensions, for example masculine and feminine)

- Synergy (Sy; ability to transcend dichotomies)

- Acceptance of Aggression ( $A$; ability to recognise and express natural anger)

- Capacity for Intimate Contact $(C$; ability to develop relationships independent of expectations, obligations or fear of loneliness)

\section{Procedure}

Three occupations were pre-selected by the researcher as representing 'women's work' and being appropriate for targeted sampling. Both Nursing and Primary School Teaching have been the subject of much research in this field and so are widely acknowledged as typically-female careers [5, $75,91]$. This is demonstrated, for example, by the fact that although the percentage of men in nursing has doubled over the past twenty-five years, men currently comprise only six percent of nurses, yet make up nearly fifty percent of the
U.S. population [108]. This is also applicable to general Child-Carers, their work with children being distinguished from teachers primarily on locality (not being within the formal boundaries of a school) and a relatively lower degree of required qualification (specifically, not a Postgraduate Certificate in Education). Furthermore, men account for only two percent of this workforce (Office for National Statistics, 2004); 97\% of recruits for Foundation Modern Apprenticeships (FMA) in Early Years' Care and Education being female [109]. Thus, these occupations represent careers which rely on the frequent use of feminine skills (for example, patience), have the traditional stigmatisation (for men) of being perceived as 'women's work', and the predominantly female composition reaffirms this feminisation.

Once these occupations had been selected, an intensive advertising campaign was launched to attract the attention of men who might fulfil the relevant criteria for the Experimental occupation group.

Some of these enquiries returned participants whose actual jobs were unsuitable for the Experimental group and so they were reallocated to the Control group. The remainder of this latter group were opportunistically selected from the general population.

Once the questionnaires were distributed, either in paper or email attachment format, participants were free to complete them in private and at their own leisure. Half the distributed questionnaires placed the BSRI first, while the other half began with the POI, to compensate for fatigue effects. As these questionnaires were specifically designed to obscure the exact purpose of the study (avoiding all references to gender, Self-Actualisation, Androgyny or Maslow, for example), participants were debriefed after its completion.

\section{Statistical Analysis}

While a number of methods for ascertaining the BSRI Gender Roles (Androgynous, Masculine, Feminine, Undifferentiated) have been proposed, direct median splits $[22,28]$ were utilised here, due to this methods greater validity in distinguishing between the Androgynous and Undifferentiated participants. As the current study was

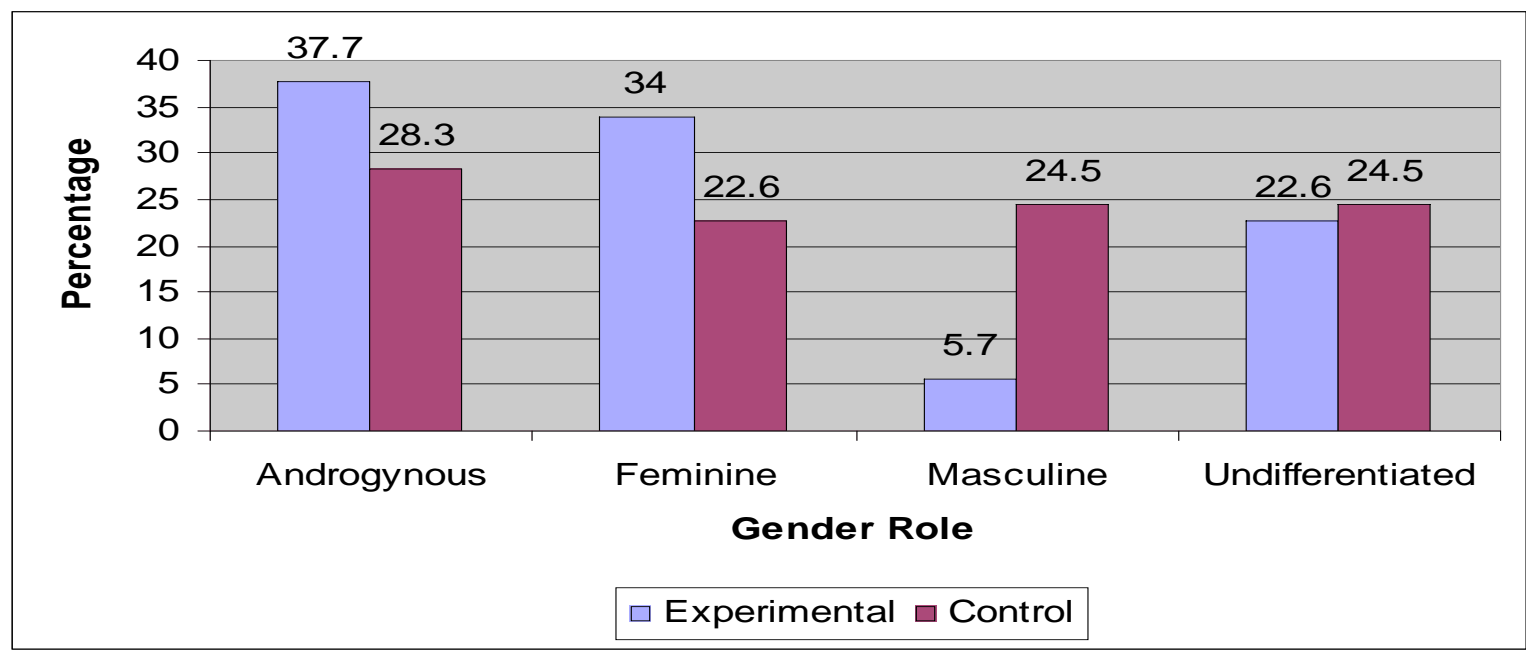

Fig. (1). Graph illustrating the prevalence of each gender role, according to group. 
conducted more than three decades after the BSRI's original development though, and included only men, new population norms were identified (as recommended in Bem, 1974 [21]). Thus, a Masculinity median cut-off point of 4.75 and a Femininity median of 4.5 were used to determine the participant's Gender Roles (see Fig. 1 below).

\section{RESULTS}

To determine whether the participants identified as Androgynous were significantly more Self-Actualised than the Non-Androgynous (hypothesis 1), the results of the three Non-Androgynous Gender Identities were aggregated. Thus, 35 participants were classified as Androgynous and 71 were deemed Non-Androgynous, regardless of occupation. T-test comparisons revealed that the Androgynous participants achieved significantly higher scores in 10 out of the 12 POI scales (Table 1), thus predominantly supporting the experimental hypothesis.

A Chi-Square Analysis found there to be a significant difference between the number of Androgynous, Feminine, Masculine and Undifferentiated individuals in the Experimental and Control populations; $\chi^{2}(3)=8.204, p=0.042$. However, the second experimental hypothesis of an association between Androgyny and the Experimental group was not supported. After collapsing the three Non-Androgynous columns, and comparing this to the Androgyny group there was no significant relationship between Androgyny and the Experimental occupation group; $\chi^{2}(1)=1.066, p=0.302$.

As suggested by Fig. (1), the significant omnibus association reported above was shown to be a result of the difference between the Masculine Men's frequencies across groups $\chi^{2}(1)=7.361, p=0.007$.

Finally, t-test comparisons of the Experimental and Control groups POI scores, across all scales, revealed no significant differences (Table 2).
Thus the final experimental hypothesis of greater selfactualisation among the experimental occupational group compared to the control group was not supported by the present study.

\section{DISCUSSION}

The current study was concerned with the nature of Androgyny in men and its role as a component of SelfActualisation. As proposed in hypothesis 1, men's acceptance of an Androgynous Gender Role was significantly more likely to correspond with a more Self-Actualised personality - manifested in ten of the twelve POI scales (Table 1) and therefore encompassing almost the entire spectrum of Self-Actualisation, not just the specific features pertaining to Androgyny. It can therefore be concluded that Androgyny is a distinctive and important feature of the Self-Actualised individual. However, the lack of significant difference between the prevalence of Androgyny (hypothesis 2) or the achievement of Self-Actualisation according to occupational group (hypothesis 3), means the gender-specific nature of the relationship between Androgyny and Self-Actualisation cannot be definitively attributed to the demands of nontraditional occupations or the adoption of solely gender atypical qualities.

To fully understand the confirmation of hypothesis 1 , an observation of the more specific differences along the POI scales is required. The scales which elicited the greatest difference between the Androgynous and Non-Androgynous groups were Spontaneity and Self-Regard. Moreover, these scales represent the only occasion in which the means achieved by the more Self-Actualised Androgynous individual's were closest to (and actually higher than) the population norms suggested for the Self-Actualised by Shostrom (1980) [42]. Self-Regard (appreciation of one's worth) in particular, had a mean of 13.26 in this sample, compared to

Table 1. t-test Results between Androgynous and Non-Androgynous Individuals on the POI Scales

\begin{tabular}{|c|c|c|c|c|}
\hline Time Competence & $15.6(3.3)$ & $14.24(3.51)$ & 1.92 & $<0.05$ \\
\hline Self Actualised Value & $20.06(2.66)$ & $18.28(3.49)$ & 2.65 & $<0.05$ \\
\hline Existentiality & $19.14(4.23)$ & $18.82(5.17)$ & 0.35 & 0.730 \\
\hline Spontaneity & $12.8(2.14)$ & $10.69(3.17)$ & 4.05 & $<0.001$ \\
\hline Self Regard & $13.26(1.76)$ & $10.94(3.12)$ & 4.88 & $<0.001$ \\
\hline Self Acceptance & $14.46(3.19)$ & $13.96(3.89)$ & 0.703 & 0.484 \\
\hline Capacity for Intimate Contact & $17.03(3.2)$ & $15.62(4.01)$ & 1.81 & $<0.05$ \\
\hline
\end{tabular}


Table 2. t-test Results between Experimental and Control Groups on the POI Scales

\begin{tabular}{|c|c|c|c|c|}
\hline Time Competence & $14.98(3.28)$ & $14.40(3.69)$ & .863 & .390 \\
\hline Self Actualised Value & $18.74(3.737)$ & $19.00(2.9)$ & .406 & .685 \\
\hline Spontaneity & $11.25(2.98)$ & $11.53(3.09)$ & -.480 & .632 \\
\hline Self Regard & $11.38(3.133)$ & $12.04(2.73)$ & 1.157 & .250 \\
\hline Self Acceptance & $13.70(3.8)$ & $14.55(3.52)$ & 1.195 & .235 \\
\hline Capacity for Intimate Contact & $16.34(4.09)$ & $15.83(3.52)$ & .688 & .493 \\
\hline
\end{tabular}

12.9 for the self-actualised population. This suggests that the features measured explicitly by these scales are essential to the relationship between Androgyny and Self-Actualisation. Spontaneity (defined as the 'freedom to be... oneself'; Shostrom, 1980; pp. 5) [42] can obviously be seen in the Androgynous' expression of behaviours they wish, or believe to be the most appropriate, to portray in a situation, irrespective of gender associations; even when these are in conflict with their physical Gender Identity [23, 28]. It has also been highlighted as a factor in non-conformist behaviour [54], which incongruent gender activities are often viewed as; for example, men taking care of a baby. Further evident is the need for confidence and selfassurance, to perform these actions, which embodies those with high Self-Regard scores. Thus, the ability to recognise your own preferences and act on them without fear of judgement is a highly Self-Actualising characteristic which would be needed frequently by those who demonstrate an Androgynous behavioural style.

The ability to recognise one's own preferences is also reliant on skills measured by the POI, specifically Feeling Reactivity ('sensitivity...to one's own needs and feelings'; Shostrom, 1980; pp. 5) [42] and Inner-Directedness; both of which were significantly linked to androgyny in this study. The scale Inner-Directed in particular is a fundamental characteristic of Self-Actualisation, illustrating that the individual has developed their own personal set of internalised morals. The strength of the difference found here exemplifies how Androgyny does not just enable a more flexible perspective of Gender but encourages greater overall psychological development, and therefore seems to lead to a more wholly Self-Actualised individual. This is further supported by the significantly higher scores attained by the Androgynous on Time-Competence and Self-Actualising Values; as both are typically deemed to be basic indicators (along with Inner-Directed) of Self-Actualisation; when a more complete profile is unavailable [44]. The consistency and strength of the significances seen across these scales also alleviates concerns that the particularly high Self-Regard could be reflecting a tendency for these individuals to 'overemphasise' their positive skills, rather than truly identifying with the full range of even negative behavioural traits; as has previously been found in Androgynous men [69]. This point was further supported by the fact that one of the only two scales where no significant difference was found was the Self-Acceptance scale (recognising own failings) which demonstrates that when it comes to accepting one's weaknesses the androgynous population does not excel.

Synergy represents the ability to integrate interconnected dichotomies, as they are not 'opposites at all' (Shostrom, 1980; pp. 18) [42]; and is the closest thing to 'a measure of Androgyny' within the POI itself. Additionally, this scale is usually paired with Nature of Man as an individual who scores highly on both is able to resolve the conflicting aspects of humanity (for example, good-evil) to see man in an essentially positive way. Along with high Self-Regard, this again alludes to the greater cognitive stability bestowed by Androgyny, reinforcing the idea that, like the SelfActualised, Androgynous individuals have achieved an enhanced degree of psychological wellbeing [10, 14, 36]. Acceptance of Aggression was also greater amongst the Androgynous, despite more forcefulness usually being acceptable for men in general [21]. However, it is possible that due to the increasing criticism of 'Hyper-Masculinity' in modern society, it is only those with a more wholly SelfActualised persona who have the confidence (again reflecting Self-Regard) to admit and accept their anger. This further illustrates how Androgyny not only utilises more SelfActualising skills, but may in fact encourage more complete Self-Actualisation. Additionally, the Androgynous' Capacity for Intimate Contact demonstrates that, as expected, they possess a greater degree of femininity. This data reinforces 
the idea that it is a Gender Role incorporating both masculine and feminine aspects; namely androgyny, which is related to greater Self-Actualisation.

While Guyot and Vollemaere's (1983) [71] Masculine Model of Self-Actualisation is still soundly rejected, certain aspects of these results do suggest that a male dimension remains strongly influential in the participants' experience of Androgyny and Self-Actualisation. To begin with, Existentiality (the ability to adapt principles to individual situations) was not significantly higher in the Androgynous, despite the seemingly obvious conceptual connection between cognitive flexibility and the integration of diametric gender traits. However, Gilligan (1993) [110] has explicitly argued that the natural orientation of men's morality is to a more rule and system based method of reasoning; which would correspond with a 'rigid adherence to principles' (Shostrom, 1980; pp. 5) [42]. Thus, the lack of difference found here might be an example of how Androgynous men retain a core of masculinity, while also being able to admit the utilisation of more Feminine behaviours. Similarly, Self-Regard has already been highlighted as the scale on which the Androgynous displayed their highest scores, and is of particular interest, as Self-Acceptance (with which it is typically paired) elicited no differences. In combination, Self-Regard and SelfAcceptance reflect Bakan's (1966) [14] assertion that Agency mediated by Communion (that is masculine tendencies towards power and confidence, balanced by more effeminate understanding and social responsibility) represents the ideal personality; and is an essential mark of the absolute achievement of Self Actualisation. What the present study seems to identify however, is Self-Regard in isolation, which can in fact be a reflection of arrogance and pride. These have been identified as typically male flaws (Kelly et al, 1977) [69], and again reiterate that these men have not achieved Androgyny through emasculation, but active integration of both genders. Thus, the nature of Androgyny and Self-Actualisation in men reflects a psychological process which is distilled through a fundamentally male perspective. Furthermore, Self-Acceptance is widely agreed to be a lot harder to achieve [42] and so, provides an excellent reminder of the fact that though Androgyny may encourage greater Self-Actualisation, it does not in itself necessitate it. To conclude, while the Self-Actualised may be Androgynous, the Androgynous are not always fully Self-Actualised.

Although the number of Androgynous individuals was higher in the experimental group in comparison with the control group, this difference was found to be nonsignificant (thereby rejecting hypothesis 2). As a result of that a clear relationship between Androgynous Gender Role and female-gender related occupations cannot be concluded. However, the significantly lower number of Masculine men in this domain does indicate that Gender Role remains a strong factor in motivating occupational choices. Aside from their high identification with masculine attributes (as these were also rated well by the Androgynous) or potential concerns about being judged for inappropriate behaviour, these were men who had explicitly stated that the more feminine style traits listed on the Bem Inventory were only 'Occasionally True' of them; and so were unlikely to find the work conducted in these female-gender related jobs appealing. As Fig. (1) clearly illustrates, these results were influenced by the prevalence of men with a specifically Feminine Gender Role. Whereas it was assumed that the greater appreciation of femininity required for being successful in 'women's work' would result in Androgyny (with these men retaining aspects of their essential masculinity), an equivalent number of men can be seen to have actually 'crossed-over' to a Female Identity. To clarify: this 'cross-typed' Gender Role is not explicitly preferable in Typically-Female occupations, but is as common as Androgyny. These facts obviously led to the rejection of the third hypothesis; since those individuals who were more highly self-actualised were not found to be significantly more prevalent in the experimental compared with the control groups, no significant differences in the levels of Self-Actualisation were found between these groups. As another possible explanation for the failure to support hypotheses 2 and 3, it should be noted that while Androgynous individuals may find non-traditional gender work more attractive than other highly sex-typed men, this does not make them any less likely to be attracted to gender non-specific work (included in the Control group); instead it might be that gender associations are just not considered by them [84].

Given the inherently feminine nature of the criteria for the Experimental group, the likelihood of cross-typed men is not unexpected. What remains surprising however is the prevalence of Feminine men in the Control group; Fig. (1) suggests this cross-typed Gender Role is actually on a par with the more traditionally assumed Masculine Role in the control group. Looking back to the population distributions provided by Bem [23], Feminine Men accounted for just $16 \%$ of the male population, while Masculine men were the norm at 37\%; to reiterate, the Masculine Gender Role represented the most common Gender Identity utilised by men, whereas a Feminine Gender Role was the rarest. Additionally, this increased femininity is not the result of an overtly homosexual bias to the participant sample; this potentially feminised sexuality accounting for only $6.6 \%$ of the tested population, which is concurrent with the $6 \%$ homosexual population which is proposed to represent British society [111]. This suggests that whereas Bursik (1995) [66] argued that feminine characteristics were devalued by men, their perceived utility is much higher today; indicating that the results of the present study are reflecting a much wider social trend. This is supported by Robinson's (1980) [112] findings that younger people's Gender Role behaviour is increasingly 'egalitarian'; sons in particular demonstrate personalities of a more Androgynous nature than their fathers [113]. This has been attributed to a number of social factors including the feminisation of the workplace, the rise of 'Metro-sexuality' and a 'Crisis of Masculinity' [114] through the devaluation of typically-male traits.

Therefore, as could be inferred from the present results, Gender Roles now appear to be tending towards a more even distribution (ranging between only twenty-two and twentyeight per cent in this sample). This indicates that the gender specific desirability of different characteristics, as relied upon by Gender measures like the BSRI, may be largely out- 
dated. Ozkan and Lajunen (2005) [115] for example, found that Turkish students rated a significant number of the BSRI's supposedly masculine attributes as equally socially desirable for men and women; including assertive, dominant and self-sufficient. Instead of denoting behavioural styles with a Gender Role then, Ballard-Reich and Elton (1992) [116] suggest that terms such as Instrumentality and Expressiveness, or Self-Directed and Other-Orientated, (reflecting the original trait research of Parson \& Bales, 1955 [12], and Reisman, 1950 [39]) may be more appropriate. Thus, different personalities would be identified independent of potential gender connotations; assertiveness being a sign of a more Instrumental individual, for example, rather than a 'Masculine' individual.

This is not the same as a conversion to widespread Androgyny however, as it implies that individuals are equally likely to represent, what Bem (1974) [21] would have deemed, a cross-typed Gender Role as a personality, which specifically integrates typically diametric behaviours, depending on their own personal preferences. Interestingly, this in fact reflects Bem's [21] recognition that 'androgyny contains ... the seeds of its own destruction... [as] when [it] becomes a reality' (pp. 1053) gender distinctions will be rendered irrelevant. While it may be over-ambitious to conclude that this fundamental change has occurred, the present study indicates that it is a serious possibility for the direction of modern society. Furthermore, this may in fact diminish the relationship between the Androgynous and SelfActualisation, as if it becomes the 'norm' Androgyny will no longer require the degree of autonomy, confidence and flexibility with which it currently encourages greater SelfActualisation. Thus, a re-evaluation of the manner in which behavioural roles and psychological identities are measured and understood is an important focus for future research.

As no significant differences arose between the Experimental and Control groups' POI scores (rejecting hypothesis 3) it cannot be assumed that there is anything inherently Self-Actualising about these occupations, or the men who choose to pursue them. It seems likely, as a possible explanation of these results, that assumptions about the greater number of Self-Actualising skills required by men in TypicallyFemale jobs (due to either social responsibility or nonconformity factors), have been confounded by potential sector-gender distinctions. For example, while to the lay population a nurse is a nurse, an essential part of the training for these individuals is choosing a specialisation, and these have been shown to have distinctly robust gender differences. Therefore, male nurses typically enter the mental health, accident and emergency, theatre and surgical fields [84, 117], where there is perceived to be a greater 'risk of aggression or violence' (Simpson, 2005; pp. 374) [91]. Squires (1995) [118] even suggested this enables men to minimise Gender Role conflict, rather than overcome it in the manner of the Androgynous. Management has also been highlighted as preferable, illustrating the 'Glass Escalator' effect [72]; men who move into women's work being 'fast-tracked' into positions of seniority [119] and thus, higher pay. This directly contradicts the occupational motivators outlined by Massuci (1966) [50]; thus (if the men in the Experimental group were attracted to the field by such extrinsic benefits) reducing the likelihood of Self-Actualisation.

Another explanation relates to Simpson (2005) [91] who has found that men in feminine occupations (including nursing and primary teaching) can be classified under one of three categories; Finders, Seekers and Settlers. Though Seekers and Settlers both demonstrated a more active transition into and actual desire for their present jobs (Settlers in particular being motivated by intrinsic and practical aspects of their career), Finders were typically identified by either having initially failed to attain a more prestigious job within the same field or 'embarrassment, discomfort and shame' (pp. 372) over the femininity of the job in question. This type of attitude is distinctly not Self-Actualising, suggesting that these individuals are particularly un-attuned to their 'selves' (essential for Inner-Directed, Feeling Reactivity, Spontaneity, Self-Regard, Self-Acceptance, Acceptance of Aggression and Capacity for Intimate Contact). If the sample of non-traditionally employed men in the present study consisted of a significant number of Finders, or those with a similar attitude, it is unsurprising they failed to demonstrate greater $P O I$ scores than the general male population, as their achievement of Self-Actualisation seems highly improbable. Thus, it seems that future research into the relationship between Androgyny and Self-Actualisation in occupations needs to operationalise these internal variations more stringently.

\section{CONCLUSION}

The present study further substantiates the argument for a relationship between a more flexible perception of gender, and thus possession of an integrated Gender Identity, and greater Self-Actualisation and spiritual health. Additionally, it increases the validity and reliability of previous research in this area; studies using the BSRI to determine Androgyny $[21,23,63,66]$ consistently support the theoretical advantages of such a character (as was found here) and so it seems likely that conflicting results are caused by less appropriate measures of Gender Role; for example the Sex Role Survey [25]. This is further reinforced by the persistence of positive scores on alternative tests of Self-Actualisation (specifically the $P O I$ here), and thus strengthens the utility of making comparisons with previous results obtained by either the $S C T$ or general comparisons with isolated Self-Actualising traits; for example, Self-Esteem [66]. The sheer range of scales on which significant differences were attained in the present study also indicates that the strength of this association is highly robust and a true reflection of the full breadth of SelfActualising qualities. Unsurprisingly though, a somewhat masculine slant to Androgyny and Self-Actualisation is also recognised to be characteristic of these concepts in men. However, the changing nature of Gender Concepts in modern society means that this relationship may have to be re-categorised as one between those who identify highly with an extensive range of diverse attributes, rather than an Androgynous Gender Role per se. Thus, the most important issue to arise in the course of this investigation is that it is the fundamental manner in which we measure and identify individual characteristics, whether Gender Role or Self- 
Actualisation, which requires continued and rigorous methodological assessment, to ensure they continue to effectively reflect the population of the day.

\section{REFERENCES}

[1] Bem S. Gender schema theory: a cognitive account of sex typing. Psychol Rev 1981; 88: 354-64.

[2] Maslow AH. Toward a psychology of being. 2nd ed. Princeton, N.J.: Van Nostrand 1968.

[3] Maslow A H. A theory of human motivation. Psychol Rev 1943; 50(4): 370-96.

[4] Gottfredson LS. Using Gottfredson's theory of circumscription and compromise in career guidance and counselling. In: Brown SD, Lent RW, Eds. Career development and counselling: putting theory and research to work. New York: Wiley 2005; pp. 71-100.

[5] Coré F. The continuing saga of labour market segregation. OECD Observer [online]. April 1999. Available from: http://www. oecdobserver.org/news/fullstory.php?aid=88

[6] Simpson JA, Weiner ESC, Eds. The Oxford English Dictionary. 2nd ed. Oxford: Oxford University Press 1989.

[7] Freud S. Collected papers. Clinical papers; papers on technique. New York: Basic Books 1924; vol. 2.

[8] Bem S. Bem sex-role inventory professional manual. Palo Alto, CA: Consulting Psychologists Press 1981.

[9] Lefkowitz ES, Zeldow PB. Masculinity and femininity predict optimal menta health: a belated test of the androgyny hypothesis. J Pers Assess 2006; 87(1): 95-101.

[10] Block JH. Conceptions of sex-role: some cross-cultural and longitudinal perspectives. Am Psychol 1973; 28: 512-26.

[11] Crawford DS. Liberal androgyny: "Gay Marriage" and the meaning of sexuality in our time. Communio 2006; 33: 240-65.

[12] Parson T, Bales R. Family, Socialization and interaction process. Glencoe, Ill.: Free Press 1955.

[13] Guttman D. Women and the conception of ego strength. Merrill Palmer Q 1965; 11: 229-40.

[14] Bakan D. The Duality of human existence. Chicago: Rand McNally 1966.

[15] Feingold A. Gender differences in personality: a meta-analysis. Psychol Bull 1994; 116: 429-56.

[16] Maccoby EE, Jacklin CN. The psychology of sex differences. Stanford, CA: Stanford University Press 1974.

[17] Costa PT, Terracciano A, McCrae RR. Gender differences in personality traits across cultures: robust and surprising findings. J Pers Soc Psychol 2001; 81: 322-31.

[18] Kagan J. Acquisition and significance of sex typing and sex role identity. In: Hoffman M, Hoffman L, Eds. Review of Child Development Research. New York: Sage Foundation 1964.

[19] Kohlberg L. A cognitive-development analysis of children's sex-role concepts and attitudes. In: Maccoby EE, Ed. The Development of Sex Differences. Stanford, CA: Stanford University Press 1966.

[20] Caselli D. Androgyny in modern literature (review). MFS Modern Fiction Stud 2008; 54(4): 926-9.

[21] Bem S. The measurement of psychological androgyny. J Consult Clin Psychol 1974; 42: 155-62.

[22] Spence J, Helmreich R, Stapp J. The personal attributes questionnaire: a measure of sex-role stereotypes and masculinity-femininity. J Suppl Abstract Serv Catalogue Select Documents Psychol 1974; 4: 43 .

[23] Bem S. Sex-role adaptability: one consequence of psychological androgyny. J Pers Soc Psychol 1975; 31: 634-43.

[24] Russell G, Bowman L. Work and family: current thinking, research and practice. Department of Family and Community Services, Commonwealth of Australia Canberra 2000.

[25] Nettles E, Loevinger J. Sex role expectations and ego level in relation to problem marriages. J Pers Soc Psychol 1983; 45: 676-87.

[26] UK, Equal Opportunities Commission. The Gender Agenda. [online]. November 2007. Available from: http://www.genderagenda.co.uk/downloads/GBAgendaBooklet.pdf

[27] Jones W, Chernovetz M, Hansson R. The enigma of androgyny: differential implications for males and females? J Consult Clin Psychol 1978; 46(2): 298-313.

[28] Bem S, Martyna W, Watson C. Sex typing and androgyny: further explorations of the expressive domain. J Pers Soc Psychol 1976; 34: 1016-23.
[29] Ramanaiah NV, Detwiler FRJ, Byravan A. Sex-role orientation and satisfaction with life. Psychol Rep 1995; 77: 1260-2.

[30] Lubinski D, Tellegen A, Butcher JN. The relationship between androgyny and subjective indicators of emotional well-being. J Pers Soc Psychol 1981; 40: 722-30.

[31] Norlander T, Erizon A, Archer T. Psychological androgyny and creativity: dynamics of gender-role and personality trait. Soc Behav Pers Int J 2000; 28(5): 423-37.

[32] Vonk R, Ashmore RD. The multifaceted self: androgyny reassessed by open-ended self descriptions. Soc Psychol Q 1993; 56: 278-87.

[33] Bem S, Lenney E. Sex typing and the avoidance of cross-sex behaviour. J Pers Soc Psychol 1976; 33: 48-54.

[34] Vogel DL, Wester SR, Heesacker M, Madon S. Confirming gender stereotypes: a social role perspective. Sex Roles 2003; 48(11/12): 519-28.

[35] Cheng C. Processes underlying gender-role flexibility: do androgynous individuals know more or know how to cope? J Pers 2005; 73 : 645-74.

[36] Kravetz D, Jones LE. Androgyny as a standard of mental health. Am J Orthopsychiatry 1981; 51: 502-9.

[37] Stake JE. Integrating expressiveness and instrumentality in real-life settings: a new perspective on the benefits of androgyny. Sex Roles 1997; 37: 541-64.

[38] Maslow AH. Self-actualizing people: a study of psychological health. In: Moustakas C E, Ed. The self: explorations in personal growth. New York: Harper \& Row 1956.

[39] Riesman D. The lonely crowd. New Haven: Yale University Press 1950.

[40] Perls F, Hefferline R, Goodman P. Gestalt therapy: excitement and growth in the human personality. New York, NY: Julian 1951.

[41] Loevinger J. Ego development: conceptions and theories. San Francisco: Jossey Bass 1976.

[42] Shostrom EL. Manual for the personal orientation inventory. California: Educational and Industrial Testing Service 1980.

[43] Masters G. Conceptualising and researching student wellbeing. In Proceedings of Australian Council for Educational Research (ACER) Conference 2004: Supporting Student Wellbeing. Camberwell VIC, Australia: ACER 2004; pp. 2-6.

[44] Shostrom EL. Personal orientation inventory: an inventory for the measurement of self-actualization. California: Edits 1966.

[45] Maslow AH. The farther reaches of human nature. Penguin Books, Arkana 1993. (Originally published in 1971 by Viking Press.)

[46] Ivtzan I. Self actualisation: for individualistic cultures only? Int J Humanist Ideol 2008; 1(2): 111-38.

[47] Loevinger J, Wessler R. Measuring ego development. Construction and use of a sentence completion test. San Francisco: Jossey-Bass 1970.

[48] Pfaffenberger AH. Optimal adult development: an inquiry into the dynamics of Growth. J Humanist psychol 2005; 45: 279-301.

[49] Choy WCW, Moneta G. The interplay of autonomy and relatedness in Hong Kong Chinese single mothers. Psychol Women Quart 2002; 26: 186-99.

[50] Massuci MJ. Psychological health and occupational perceptions in a selected sample. Unpublished Doctoral Dissertation, Syracuse University. In Knapp RR. POI Handbook. 2nd ed. San Diego: EdITS Publishers 1966.

[51] Olczak PU, Goldman JA. Relationship between self-actualisation and assertiveness in males and females. Psychol Rep 1981; 48: 931-7.

[52] Ivtzan I, Moon HS. The beauty of self-actualisation: linking physical attractiveness and self-fulfilment. Eur J Psychol 2008b 16: 34-46.

[53] Crosson S, Schwendiman G. Self-actualisation as a predictor of conformity behaviour. Unpublished Manuscript, Marshall University. In Knapp R R. POI Handbook, 2nd ed. San Diego: EdITS Publishers 1972.

[54] Zimmerman SF, Smith KH, Pederson DM. The effect of anticonformity appeals on conformity behaviour. J Soc Psychol 1970; 81: 93-103.

[55] Cook-Greuter S. Postautonomous ego development: a study of its nature and measurement. Cambridge MA Unpublished doctoral dissertation. Harvard University 1999.

[56] Cook-Greuter S. Mature ego development: a gateway to ego transcendence? J Adult Dev 2000; 7(4): 227-40. 
[57] Reiss S, Havercamp SM. Motivation in a developmental context: a new method for studying self-actualization. J Hum Psychol 2005; 45(1): 41-53.

[58] Block J H. Lives through time. Berkeley, Calif.: Bancroft Books 1971.

[59] Heilbrun AB. Sex role, instrumental-expressive behaviour, and psychopathology in females. J Abnorm Psychol 1968; 73: 131-6.

[60] Hjelle LA, Butterfield R. Self-actualization and women's attitudes toward their roles in contemporary society. J Psychol 1974; 87: 225-30.

[61] Doyle JA. Self-actualisation and attitudes towards women. Psychol Rep 1975; 37: 454-58.

[62] Spence J, Helmreich R, Stapp J. Ratings of self and peers on sex role attributes and their relation to self-esteem and conceptions of masculinity and femininity. J Pers Soc Psychol 1975; 32: 2939.

[63] Schiff E, Koopman E. The relationship of women's sex role identity to self esteem and ego development. J Psychol 1978; 98: 299-305.

[64] Costos D. Sex role identity in young adults: its parental antecedents and relation to ego development. J Pers Soc Psychol 1986; 50: 60211.

[65] Prager K, Bailey J. Androgyny, ego development, and psychosocial crisis resolution. Sex Roles 1985; 13: 525-36.

[66] Bursik K. Gender-related personality traits and ego development: differential patterns for men and women. Sex Roles 1995; 32: 60116 .

[67] Schwarz K, Robins C. Psychological androgyny and ego development. Sex Roles 1987; 16: 71-81.

[68] Berzins J, Welling M, Wetter R. A new measure of psychological androgyny based on the personality research form. J Consut Clin Psychol 1978; 46: 126-38.

[69] Kelly JA, Worrell J. New formulation of sex roles and androgyny: a critical review. J Consult Clin Psychol 1977; 45: 1101-15.

[70] Kelly JA, Caudill MS, Hathorn S, O'Brien CG. Socially undesirable sex correlated characteristics: implications for androgyny and adjustment. J Consult Clin Psychol 1977; 45: 1185-6.

[71] Guyot GW, Vollemaere E. Biological sex, sex-role, and selfactualization of college students, Paper presented at the Annual Convention of the Southwestern Psychological Association 29th, San Antonio, TX 1983.

[72] UK, Office for National Statistics. Labour market analysis and summary. September 2006 Assessment [online]. Available from: http://www.statistics.gov.uk/downloads/theme_labour/LMT_ Oct06.pdf

[73] U.S. Department of Labor, Bureau of Labor Statistics. Employment and Earnings, Annual Averages and the Monthly Labor Review 2007.

[74] Australian Bureau of Statistics. Labour Force, Australia, Spreadsheets, December 2006, Table 02, Labour force status by sex Seasonally Adjusted, ABS Cat. No. 6202.0.55.001. Canberra: Australian Bureau of Statistics 2006.

[75] Williams CL. The glass escalator: hidden advantages for men in the "female" professions. Soc Problems 1992; 39: 253-68.

[76] Thomson E, McKay A, Campbell G, Gillespie M. Jobs for the boys and the girls: promoting a smart, successful and equal Scotland. [online]. 2005. Available from: http://www.equalityhumanrights.com/ Documents/EOC/PDF/Research/Occupational20segregation\% 20GFI\%20Scotland\%20final\%20report_feb_2005.pdf

[77] Cross S, Bagilhole B. 'Girls' jobs for the boys? men, masculinity and non-traditional occupations'. Gender Work Organ 2002; 9(2): 204-26.

[78] Gauthier J, Kjervik D. Sex-role identity and self-esteem in female graduate nursing students. Sex Roles 1982; 8: 45-55.

[79] Eichinger J, Heifefetz LH, Ingraham C. Situational shifts in social role orientation: correlates of work satisfaction and burnout among women in special education. Sex Roles 1991; 25: 427-42.

[80] Bushardt SC, Fowler A, Caveny R. Sex-role behaviour and leadership: an empirical investigation. Leadership Organ Dev J 1987; 8: 13-6.

[81] Cummings S. Attila the hun versus attila the hen: gender socialization of the American nurse. Nurs Adm Q 1995; 19(2): 19-29.

[82] Kirchmeyer C. Gender roles in a traditionally female occupation: a study of emergency, operating, intensive care, and psychiatric nurses. J Vocat Behav 1997; 50(1): 78-95.
[83] Gottfredson LS, Lapan RT. Assessing gender-based circumscription of occupational aspirations. J Career Assess 1997; 5: 419-41.

[84] Muldoon O, Reilly J. Career choice in nursing students: gendered constructs as psychological barriers. J Adv Nurs 2003; 43(1): 93100 .

[85] Wolfram HJ, Mohr G, Borchert J. Gender role self-concept, gender-role conflict, and well-being in male primary school teachers. Sex Roles 2009; 60(1-2): 114-27.

[86] Meece J. Trends in women's employment in the early 21 st century. Educ Res Evaluat 2006; 12(4): 297-303

[87] Cotter D, DeFiore J, Hermsen J, Kowalewski B, Vanneman R. Occupational gender desegregation in the 1980s. Work Occup 1995; 22(1): 3-21.

[88] Jacobs J, Lim S. Trends in occupational and industrial sex segregation in 56 countries, 1960-1980. Work Occup 1992; 19(4): 45086.

[89] Feinman S. Approval of cross-sex-role behaviour. Psychol Rep 1974; 35: 643-8.

[90] Bagilhole B, Cross S. It never struck me as female: investigating men's entry into female-dominated occupations. J Gender Stud 2006; 15(1): 35-48.

[91] Simpson R. Men in non-traditional occupations: career entry, career orientation and experience of role strain. Gender Work Organ 2005; 12(4): 363-80.

[92] UK, Office for National Statistics. Annual Survey of Hours and Earnings (ASHE), [online]. 2007. Available from: http://www. statistics.gov.uk/cci/nugget.asp?id=285

[93] MacLure M. Arguing for your self: identity as an organising principle in teachers' Jobs and lives. Br Educ Res J 1993; 19(4): 31122.

[94] Ilardi RL, May WT. A reliability study of shostrom's personal orientation inventory. J Hum Psychol 1968; 8: 68-72.

[95] Bartlett P, Hind R, Taylor W. A comparison of the career aspirations of degree and P2000 diploma graduates from UK nursing programmes. J Nurs Manage 1999; 7: 37-43.

[96] Fox DJ, Diamond LK, Walsh RC, Knopf L, Hodgin J. The nursing student in the hospital setting. Hospitals 1963; 37: 50-6.

[97] Smith L. A follow up study of the bachelor of nursing graduates 1982-1990, University of Glasgow, Scotland. J Adv Nurs 1993; 18: $1840-8$.

[98] Hayes R. Men's decisions to enter or avoid non-traditional occupations. Career Dev Q 1986; 35(2): 89-101.

[99] Annandale E, Hunt K. Masculinity, femininity and sex: an exploration of their relative contribution to explaining gender differences in health. Soc Health Ill 1990; 12: 24-46.

[100] Flaherty JF, Dusek JB. An investigation of the relationship between psychological androgyny and components of self-concept. J Pers Soc Psychol 1980; 38(6): 984-92.

[101] Glazer CA, Dusek JB. The relationship between sex-role orientation and resolution of eriksonian developmental crises. Sex Roles 1985; 13(11/12): 653-61.

[102] Waterman AS, Whitbourne SK. Androgyny and psychosocial development among college students and adults. J Pers 1982; 50(2): 121-33.

[103] Klavetter RE, Morgan RE. Stability and internal consistency of a measure of self-actualization. Psychol Rep 1967; 21: 422-4.

[104] Knapp RR. POI Handbook, $2^{\text {nd }}$ ed. San-Diego, CA: EdITS Publishers 1990 .

[105] Shostrom EL. A test for the measurement of self-actualization. Educ Psychol Measure 1964; 24: 207-18.

[106] Warehime RG, Foulds ML. Social desirability response sets and a measure of self-actualisation. J Hum Psychol 1973; 13: 8995.

[107] Steilberg B. The personal orientation inventory: the effects of "fake good" instructions on student nurses. (Duth) Gedrag: Tijdschr Psychol 1976; 4: 108-13.

[108] Kepshire B. Bring passion to your workplaces everyday. Men Nurs 2006; 3: 4-5

[109] Fuller A, Beck, V, Unwin L. The gendered nature of apprenticeship: employers' and young people's perspectives. Educ Train 2005; 47(4/5): 298-311.

[110] Gilligan C. In a different voice: psychological theory and women's development. 2nd ed. Cambridge, MA: Harvard University Press 1993. 
[111] Govan F. Six percent of population are gay or lesbian, according to Whitehall figures. UK: Telegraph 2005.

[112] Robinson J. Housework technology and household work. In: Fenstermaker S, Ed. Women and household labour. Beverly Hills, CA: Sage 1980; pp. 53-68.

[113] Guastello D, Guastello S. Androgyny, gender role behaviour, and emotional intelligence among college students and their parents. Sex Roles 2003; 49: 663-84.

[114] McDowell L. The trouble with men? young people, gender transformations and the crisis of masculinity. Int J Urban Region Res 2000; $24: 201-9$
[115] Özkan T, Lajunen T. Masculinity, femininity, and the bem sex role inventory in Turkey. Sex Roles 2005; 52: 103-10.

[116] Ballard-Reisch B, Elton M. Gender orientation and the bem sex role inventory: a psychological construct revisited. Sex Roles 1992; 27: 291-306

[117] Culkin J, Tricario D, Cohen F. Sex role orientation of nursing students at a community college. Psychol Rep 1987; 60: 948-50.

[118] Squires T. Men in nursing. Regist Nurse 1995; 58(7): 26-8.

[119] Davies C. Gender and the professional predicament in nursing. Buckingham: Open University Press 1998

(C) Ivtzan and Conneely; Licensee Bentham Open.

This is an open access article licensed under the terms of the Creative Commons Attribution Non-Commercial License (http://creativecommons.org/licenses/by$\mathrm{nc} / 3.0 /$ ) which permits unrestricted, non-commercial use, distribution and reproduction in any medium, provided the work is properly cited. 